DOI: $10.30972 /$ eitt.704768

\title{
Dime con qué te cubres y te diré quién eres: estrategias de educación no formal como herramienta de conservación
}

\author{
Cesar A. Obregón', Verónica L. Romero², Angelina M. Godoy³, \\ Bárbara G. Romero³, Patricia M. Fernández ${ }^{3}$, Martin M. Kowalewski4
}

\section{Resumen}

En el marco del proyecto "Conocer para conservar nuestra diversidad biológica", guías del área de Educación Ambiental de la Estación Biológica Corrientes (EBCO, CONICET) y docentes y alumnos/as de la Facultad de Ciencias Exactas y Naturales y Agrimensura (FaCENA, UNNE) realizaron actividades de taller en el aula y en el Parque Provincial San Cayetano para estudiantes de primer grado pertenecientes a la Escuela Primaria No 553 "San Cayetano" (San Cayetano, Corrientes). El objetivo de estas actividades fue la comprensión de los distintos tipos de coberturas que tienen los animales terrestres y acuáticos de la Región. La metodología empleada incluyó la articulación entre el contenido curricular trabajado por los docentes de la escuela y las actividades ofrecidas por el área de Educación ambiental, desde la identificación de estructuras, las especies animales que las poseen y los ambientes que habitan. Los conceptos desarrollados giraron en torno a las adaptaciones de los animales, los tipos de cobertura que poseen (pelos, escamas, plumas) y sus

\footnotetext{
1'Licenciado en Ciencias Biológicas, Estación Biológica Corrientes (EBCo, CCT, CONICET), FaCENA (UNNE), cesarale89@gmail.com

${ }^{2}$ Doctora en Biologia, Estación Biológica Corrientes (EBCo, CCT, CONICET), FaCENA (UNNE), lorenromer@yahoo.com.ar 3Integrantes del área de Educación Ambiental, Estación Biológica Corrientes (EBCo, CCT, CONICET), edu.ambientalebco@gmail.com

${ }^{4}$ Doctor en Antropología, Director Estación Biológica Corrientes, (EBCo, CCT, CONICET), martinkow@gmail.com
} 
formas corporales. Estos conceptos, repasados en aula con un fuerte componente de lecto-comprensión fueron puestos en práctica a partir de una visita guiada a un ambiente natural protegido, el Parque Provincial San Cayetano (San Cayetano, Corrientes). Tanto los conceptos teóricos como los prácticos fueron implementados a partir del juego, lo que impactó positivamente sobre la asimilación de los conceptos en los niños y niñas de entre 6 a 7 años. Por lo tanto, estas actividades permiten concluir que la exploración del conocimiento en espacios no formales en articulación con el curriculum refuerza significativamente el conocimiento de la naturaleza y promueve valores de conservación.

Palabras clave: Sensibilización. Ambiente. Curricular. Articulación

\section{Introducción}

En los últimos años las estrategias de enseñanza y aprendizaje en las Ciencias Naturales han evolucionado incluyendo espacios participativos de educación ambiental con la finalidad de incorporar valores y conductas saludables con el ambiente. Se documenta que la integración de conceptos y experiencias prácticas proporciona un conocimiento aún más significativo y favorece el empoderamiento de los valores ambientales. (Posser Bravo 2019). La utilización de todos los sentidos en espacios accesibles, amplía las alternativas de exploración y acerca a los estudiantes al contexto real circundante, más allá del conocimiento formal (Vargas \& Estupiñan 2012). En este sentido, los diseños curriculares de la Educación General Básica (EGB) tienen contenidos sobre Biología, Ecología y Conservación desde el primer ciclo (Ministerio de Cultura y Educación de la Nación 1995).

En los primeros tres años de la EGB se desarrollan aspectos sobre diversidad animal y vegetal, y además se estudian los seres vivos en el nivel ecológico de organización de ecosistemas, los cuales pueden ser acuáticos, de transición y terrestres (Ministerio de Cultura y Educación de la Nación 1995). En este ciclo educativo se propone como expectativa de logro aproximar a los estudiantes a la biodiversidad en los diferentes ambientes, para identificar los animales y vegetales que allí viven y reconocer semejanzas y diferencias entre ellos, es decir, aquellas adaptaciones a su 
entorno (Gobierno de la provincia de Corrientes 1997). Por lo tanto, el eje temático del primer año en el nivel primario incluye una introducción a la diversidad animal, comportamiento, diversidad relacionada con el movimiento, la alimentación y la defensa de los organismos. Y, esto tiene importancia para generar a partir de la formación, un sujeto social comprometido con su comunidad, crítico y reflexivo, que pueda valorar críticamente sus tradiciones y patrimonio cultural para poder optar por aquellos elementos que mejor favorezcan su desarrollo integral (Luzzi 2000), además, debe ser comprometido/a hacia la conservación de los ambientes naturales y sensibilizado por las problemáticas que los impactan negativamente.

El desarrollo desde edades pequeñas, brinda oportunidades para generar espacios de reflexión acerca de las problemáticas ambientales actuales, como por ejemplo la pérdida de la biodiversidad por la fragmentación de bosques nativos debido al avance de las fronteras agro-industriales (Hansen et al. 2013), y el conocimiento de especies autóctonas amenazadas en sus ambientes (Agostini et al. 2012). De esta manera, nuestro trabajo bajo el proyecto denominado "Conocer para conservar nuestra diversidad biológica”, nos permitió generar espacios de encuentro, práctica y reflexión sobre estrategias desde la educación no formal para la enseñanza y el aprendizaje de conocimientos teóricos y prácticos de una manera más vivencial, con la meta de iniciar en aquellos valores que promuevan la conservación de la naturaleza. De esta manera, el objetivo particular de esta actividad es fortalecer el conocimiento sobre los distintos tipos de coberturas en animales nativos, sus relaciones con adaptaciones a los ambientes terrestres y acuáticos, y promover el conocimiento de la fauna local, principalmente aquella que se encuentra bajo protección en el Parque Provincial San Cayetano (Riachuelo, Corrientes).

\section{Metodología}

La escuela primaria No 553 San Cayetano se encuentra ubicada en San Cayetano (Riachuelo) a $14 \mathrm{~km}$ de la ciudad de Corrientes (Corrientes, Argentina), es una escuela semiurbana, cuyos escolares provienen de zonas rurales y semirurales de esta localidad, y cuenta con aulas que contemplan el primer y segundo ciclo de la educación primaria, además de un anexo $\mathrm{N}^{0}$ 17. El equipo de trabajo forma parte del área 
de Educación ambiental de la Estación Biológica Corrientes, un programa que está activo hace casi 10 años con distintas actividades de extensión en diferentes niveles educativos de la provincia de Corrientes. En esta oportunidad se trabajó junto a las maestras y maestros con una secuencia didáctica que incluye la unidad de diversidad animal y las adaptaciones que presentan las especies en los ambientes acuáticos y terrestres, junto a los tipos de tegumentos de los animales tales como piel y estructuras derivadas como pelos, sedas, escamas y plumas que forman una cobertura de protección mecánica contra la abrasión y perforación (Kardong 2011).

Figura 1: Charla-taller con estudiantes de primer grado de la Escuela $N^{o} 553$ San Cayetano. Foto de todas y todos los que participaron junto al equipo de la EBCo.

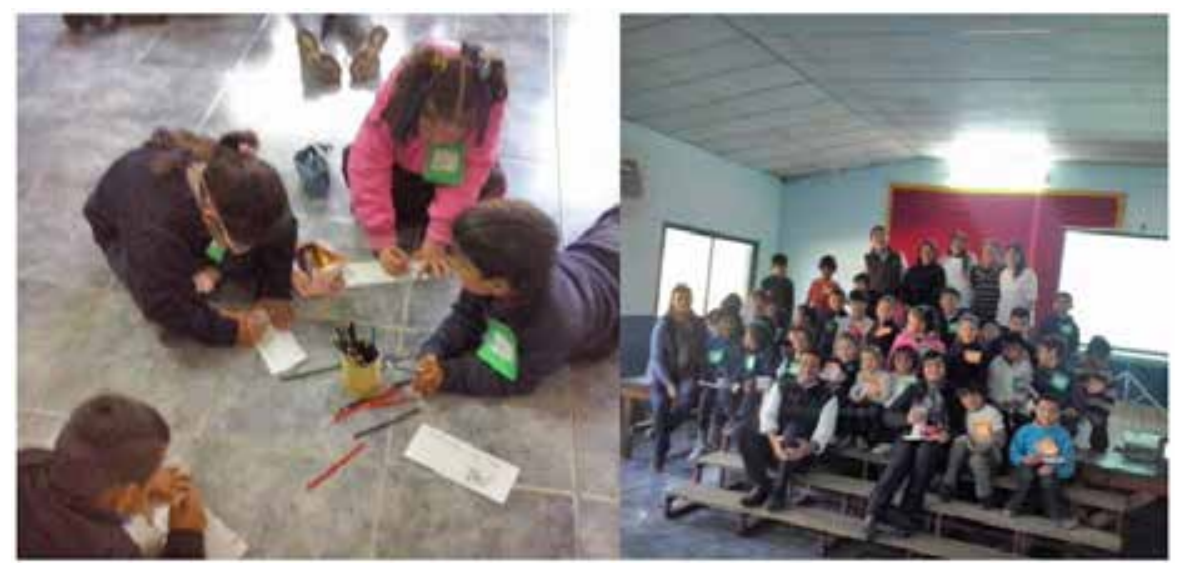

Las actividades tuvieron dos etapas un trabajo de charla-taller en el patio de la escuela y otra etapa de una salida guiada en el Parque Provincial San Cayetano (San Cayetano, Corrientes). La charla-taller se realizó el 7 de junio de 2018, en el cual participaron 25 estudiantes de entre 6 a 7 años separados en pequeños grupos de 4 a cinco integrantes y tenían como guía a un integrante del equipo de trabajo y una maestra/o (Fig. 1).

La agrupación se realizó con una actividad de juego denominada "Los elementos naturales", donde las y los niños/as reciben elementos naturales como troncos hojas, flores y luego se separan con sus compañeros que poseen el mismo elemento. Estos grupos trabajaron con ideas previas, una actividad de aplicación que incluyó la identificación de coberturas y adaptaciones de distintos animales a sus ambientes con auxilio de una ficha que permita la lecto-comprensión (Fig. 2), y un cierre de ideas trabajadas. 
Figura 2: Fichas de distintos grupos de especies de animales nativas que representan distintas coberturas (pelos, escamas, plumas) y diferentes formas de desplazamiento.
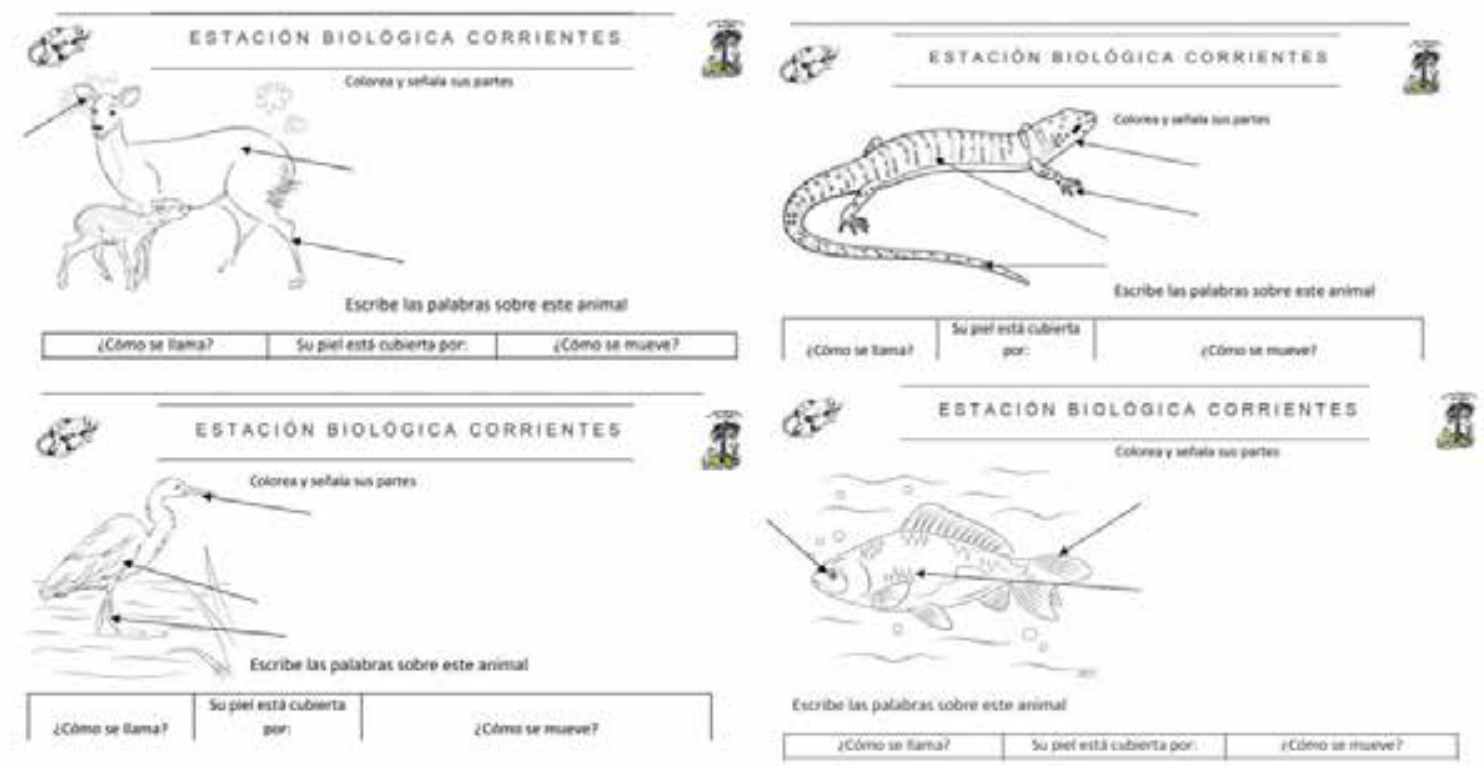

El sondeo de ideas previas consistió en la proyección de imágenes de animales autóctonos que las maestras desarrollaron como contenido durante sus clases. En el mismo se realizaban preguntas disparadoras como ¿Qué animal observan?, ¿Cómo se mueve?, ¿Dónde vive?, ¿Conocen de qué se alimenta? En la actividad de aplicación los estudiantes completaron y colorearon una ficha sobre un animal determinado especificando su nombre, tipo de cobertura y forma de movimiento (Fig. 2).

La actividad de cierre consistió en un juego didáctico llamado "Dime de que te cubres y te diré quién eres" en el cual los participantes por grupo debían utilizar el tacto para identificar material de laboratorio (pelos, plumas, escamas) y asociar que animales poseían esa cobertura.

En otra jornada de trabajo se realizó una visita guiada por los senderos de interpretación del Parque Provincial San Cayetano, donde se ubica la Estación Biológica Corrientes. Durante la visita los niños y niñas junto a las y los guías de interpretación ambiental integraron aquellos conocimientos teóricos y prácticos aprendidos en la charla-taller de manera más vivencial. Además, en el guiado se buscó la sensibilización de los y las niñas hacia la naturaleza, promoviendo valores de conservación de los ambientes locales, a través de actividades de interpretación de la natura- 
Figura 3: Visita guiada y actividades de aplicación en senderos de interpretación ambiental del Parque Provincial San Cayetano (San Cayetano, Corrientes)

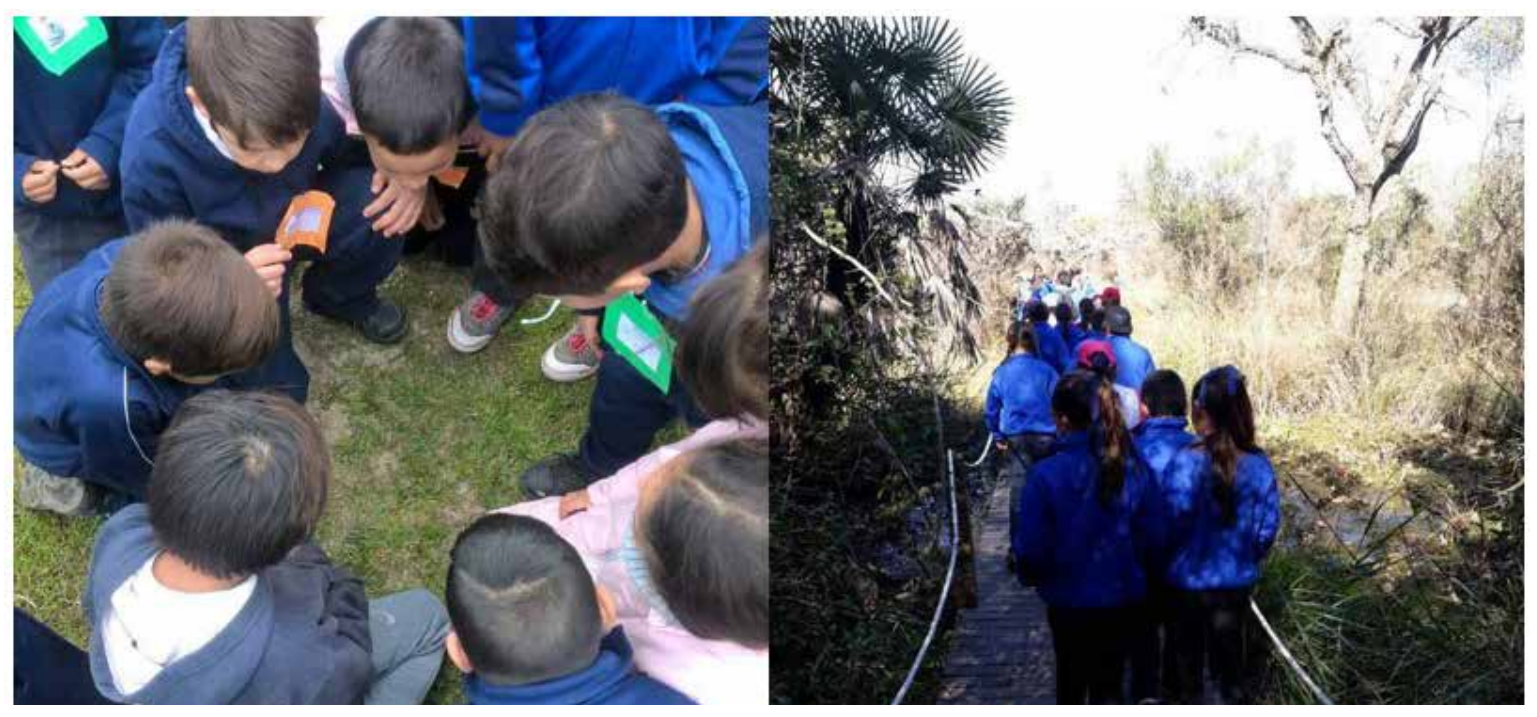

leza. Estos ambientes fueron el bosque inundable, palmares de caranday, pajonales de paja colorada, e isletas de bosques en zonas altas. Para cada ambiente los guías implementaron nuevas actividades lúdicas que describían la composición florística y la fauna característica. En este tipo de actividades se incluyen cuentos, mitos y leyendas sobre el hombre y su relación con la naturaleza lo que otorga gran valor cultural (Fig. 3).

\section{Resultados y Conclusiones}

Durante el desarrollo de la charla-taller con los 25 niñas y niños, el sondeo de ideas previas dejó en evidencia cierto conocimiento de base sobre las especies de animales ejemplificadas. Entre ellas, han reconocido a los monos aulladores negros y dorados que llaman monos carayá (Alouatta caraya), manifestando la distinción entre los machos de las hembras por el color del pelaje, también reconocieron al lobito de río (Lontra longicaudis), el oso hormiguero (Myrmecophaga tridactyla) y los zorros, sin que distingan las dos especies que habitan la región (Cerdocyon thous y Lycalopex gymnocercus). En general identificaron grupos como aves, insectos, y reptiles. En la mayoría han sabido reconocer los tipos de coberturas. La identificación del tipo de cobertura y movimiento fue señalada con claridad, ya que podían diferenciar plumas en las aves, pelos en los mamíferos y escamas en peces, 
en algunos casos se dificultó la identificación de escamas en reptiles. Las formas de desplazamientos fueron poco conocidas, a excepción de aves y peces.

En la actividad de aplicación, se trabajó sobre la lecto-escritura, de gran interés por las y los docentes. Han practicado mediante la lectura y escritura los nombres comunes de los animales, de los cuales algunos han sido de dificultad y solicitaban la ayuda docente o del integrante del equipo de trabajo. La mayor dificultad que se observó fue en la escritura, lo cual sugiere una readecuación de la ficha de actividades para que la escritura no sea una condición limitante para realizar la actividad. De todas maneras, pese a la dificultad, la predisposición de las niñas y niños ha sido muy buena.

La actividad de cierre con el juego didáctico "Dime con que te cubres y te diré quién eres" reforzó los conocimientos en un espacio dinámico y recreativo, donde demostraron un buen manejo de los contenidos previamente propuestos. Contenidos que han sido rescatados durante la visita guiada en el área protegida, en un lugar novedoso para el grupo de niñas y niños, que generó entusiasmo, nuevas inquietudes y preguntas sobre la fauna y las adaptaciones que presentan en los distintos ambientes recorridos (Figura 3.)

\section{Bibliografía}

AGOSTINI I., et al. 2012. Orden Primates. Pp. 81- 86. In: RA OJEDA, V CHILLO y GB DIAZ ISENRATH (eds.), Libro rojo de mamíferos amenazados de la Argentina. Sociedad Argentina para el Estudio de los Mamíferos.

CONSEJO FEDERAL DE EDUCACIÓN. 1995. Contenidos básicos comunes para la educación general básica. Buenos Aires, Ministerio de Cultura y Educación de la Nación.

GOBIERNO DE CORRIENTES MINISTERIO DE EDUCACIÓN. 1997. Diseño Curricular Primer Ciclo EGB. 
HANSEN M. C, et al. 2013. High-Resolution Global Maps of 21st-Century Forest Cover Change. Science, 850-853.

KARDONG, K. V. Vertebrados: Anatomía Comparada, Função e Evolução. $5^{\text {th }}$ ed. São Paulo, Roca, 2011.

LUZZI, D. 2000. La educación ambiental formal en la educación general básica argentina. Tópicos en educación ambiental, 2(6), 35-52.

NIGRO N. A. y N. LODEIRO OC AMPO. 2009. Atropellamiento de fauna silvestre en las rutas de la provincia de Misiones, Argentina. Reportes Tigreros, 2da Serie Conservación.

OKLANDER, LUCIANA; KOWALEWSKI, MARTÍN; PEKER, SILVANA; PAVÉ, ROMINA; AGOSTINI, ILARIA; HOLZMANN, INGRID; APELLANIZ, MELISA (2019). Alouatta caraya. Categorización 2019 de los mamíferos de Argentina según su riesgo de extinción. Lista Roja de los mamíferos de Argentina. Versión digital: http://cma.sarem.org.ar.

PROSSER BRAVO, G. y I. ROMO-MEDINA. 2019. Investigación en educación ambiental con menores en Iberoamérica: Una revisión bibliométrica de 1999 a 2019. Revista mexicana de investigación educativa, 24 (83): 1027-1053.

VARGAS, C. y M. R. ESTUPIÑÁN. 2012. Estrategias para la educación ambiental con escolares pobladores del páramo Rabanal (Boyacá). Revista luna azul, 34: $10-25$. 